\section{DIMENSIONES CULTURALES DE LA MOVILIDAD URBANA ${ }^{1}$}

Carlos Lange Valdés ${ }^{2}$

\section{Resumen}

La movilidad urbana, y particularmente aquella desarrollada de manera cotidiana por los habitantes de la ciudad, constituye una problemática de creciente y progresiva relevancia tanto para el funcionamiento del sistema urbano como para el desenvolvimiento de la vida social.

Si bien ella ha sido objeto de reflexión desde tiempos pretéritos, es a partir de la consolidación del paradigma de la ciudad global y de su incesante expansión en redes y flujos que su trascendencia pone en cuestión la conformación misma de "lo urbano", generando nuevas interrogantes sobre sus tradicionales enfoques de comprensión.

Lo anterior tiene particular importancia para las ciencias sociales, en la medida que éstas se enfrentan al

\section{CULTURAL DIMENSIONS OF URBAN MOBILITY 1}

Carlos Lange Valdés²

\begin{abstract}
Urban mobility, particularly that developed on a daily basis by city-dwellers, is a problem area of increasing importance for the operation of the urban system and for the development of social life. Although urban mobility has been an object of analysis for a long time, the consolidation of the global city paradigm and its unstoppable expansion allowed it to question the "urban concept", generating new queries about its traditional approaches.
\end{abstract}

This situation is of particular importance for social sciences, as they face the challenge 
desafío de ampliar su marco de comprensión respecto de sus dimensiones socioculturales que ella conlleva. Desde esta perspectiva, este trabajo establece tres planteamientos en relación al abordaje de la movilidad urbana desde las ciencias sociales. El primero busca dar cuenta de la relevancia que ésta posee como objeto de estudio. El segundo se orienta a delinear una perspectiva sociocultural de la misma. Por último, el tercer planteamiento presenta algunas interrogantes que podrían suponer líneas de investigación futuras en torno a su desarrollo.

PALABRAS CLAVE: CULTURA URBANA, MOVILIDAD URBANA, CIENCIAS SOCIALES.

Fecha de recepción: 15.11.10

Fecha de aceptación: 21.03.11

1 Este trabajo se basa en el Proyecto de Investigación FONDECYT N 1090198 "Movilidad cotidiana urbana y exclusión social urbana en Santiago de Chile".

2 Chile. Lic. en Antropología Social, U. de Chile. Mg. en Desarrollo Urbano, PUC. Estudiante de Doctorado en Ciencias Sociales y Comunicación, U. de Deusto. Académico Instituto de la Vivienda FAU Universidad de Chile.

Correo electrónico: clange@opendeusto.es of enhancing the understanding of urban mobility, as far as its socio cultural dimensions are concerned. This paper establishes three approaches about how urban mobility is addressed from a social sciences perspective. The first approach reveals its importance as object of study. The second one demarcates a socio cultural perspective. The last one poses questions that may be used for future research.

\section{KEYWORDS: URBAN CULTURE, URBAN MOBILITY, SOCIAL SCIENCES.}

Received: 15.11 .10

Accepted: 21.03.11

1 This paper is based on the FONDECYT Project N ${ }^{0} 1090198$ "Daily Urban Mobility and Urban Social Exclusion in Santiago de Chile"

2 Chile. B.A. in Social Anthropology, Universidad de Chile. Master's Degree in Urban Development, PUC. Doctoral student in Social Sciences and Communication, Universidad de Deusto. INVI Academic, FAU Universidad de Chile.

Email: clange@opendeusto.es 


\section{Relevancia de la movilidad urbana como objeto de estudio para las ciencias sociales}

La movilidad urbana constituye una de las problemáticas más importantes de la vida urbana contemporánea. Si bien el reconocimiento de su rol como medio para asegurar la accesibilidad entre las distintas áreas funcionales de la ciudad es de muy antigua data, su relevancia se ha incrementado fuertemente en la actualidad, pasando a constituirse en un factor de desarrollo político, económico y sociocultural por sí mismo.

Tal como lo ha ilustrado R. Sennett ${ }^{3}$, desde los albores del urbanismo y bajo la influencia de su proyecto de racionalización espacial, la movilidad urbana fue utilizada como un recurso fundamental para la reestructuración de las principales capitales europeas y sus modos de vida. En este sentido, su análisis de los proyectos desarrollados por J. Nash y el Barón Haussmann, en Londres y París a fines del siglo XIX, muestra cómo la movilidad urbana no sólo tuvo como objetivo mejorar la accesibilidad y la conectividad desde las periferias hacia el centro y viceversa, sino también permitió promover la regulación del uso ciudadano del espacio público

3 Sennett, 2002. y ordenar la distribución de los distintos grupos sociales al interior de la ciudad. Por medio de estos ejemplos, Sennett da cuenta de la estrecha relación entre la construcción de infraestructuras para la movilidad y la transformación de la experiencia del habitar urbano.

No obstante lo anterior, su trascendencia se ha hecho más preponderante desde fines del siglo pasado con el advenimiento del modelo de "ciudad global”. Tal como lo estableció en su momento S. Sassen ${ }^{4}$, hacia fines de los años ochenta la crisis del modelo de producción industrial o fordista, experimentada con fuerza desde mediados de los años setenta, fue dejada atrás en gran medida por la irrupción de las tecnologías de la comunicación y la informatización, dando paso a un modelo de producción de carácter postindustrial o postfordista $^{5}$. Gracias a esta transformación, los grandes centros urbanos se consolidan como "centros para la coordinación, el control y el servicio del capital global", tanto a partir de la concentración de funciones de comando a nivel político, económico, cultural, como también debido a la expansión de sus ámbitos de influencia mediante redes de información y comunicación, permitiendo su articulación a escala mundial. Bajo esta lógica, la complementariedad entre "centralidad" y "movilidad" se convierte en un requisito vital para la organiza-

Sassen, 1998

Harvey, 2004. 
ción, funcionamiento y expansión de los sistemas urbanos.

Si bien las redes informacionales y comunicacionales constituyen los medios más novedosos para la promoción de la "movilidad" bajo el actual modelo de producción, ella no solamente se consolida a partir de recursos de carácter digital. De hecho, una de las manifestaciones más visibles del nuevo modelo de producción lo constituye la proliferación de subcentralidades polifuncionales en áreas metropolitanas, las cuales permiten la articulación de las actividades productivas en amplios entornos territoriales circundantes. Bajo esta lógica, la eficiente movilidad urbana de los recursos productivos, sean éstos humanos, materiales, financieros o informacionales, pasa a constituir un imperativo funcional fundamental tanto a nivel urbano como interurbano.

Lo anterior queda de manifiesto al observar la proliferación de infraestructuras y equipamientos para la movilidad en los principales centros urbanos, que se reflejan en la importancia asignada a la construcción masiva y acelerada de medios de transporte como el metro, ferrocarriles interurbanos, carreteras urbanas e incluso vías especiales para el desplazamiento peatonal, que refuerzan los procesos de suburbanización ya referidos. Más allá de cualquier delimitación de carácter territorial, es en el dinamismo y expansión de las inversiones productivas, infraestructuras, equipamiento y recursos humanos que la condición urbana alcanza su máximo punto de concreción.

Sin embargo, y como puede desprenderse del párrafo precedente, los procesos anteriormente referidos no solamente afectan a los grandes centros urbanos en su forma -es decir, como artefactos-en su funcionalidad -es decir, como sistemas-, sino que ellos también conllevan importantes transformaciones en los modos de vida de sus habitantes. Esto ha abierto un amplio campo de debate para las ciencias sociales, instalando la interrogante respecto de los alcances que las transformaciones generadas por la movilidad urbana tienen sobre los modos de vida de los habitantes urbanos.

Ejemplos de esta situación son las propuestas generadas por autores como Venturi y Scott Brown ${ }^{6}$, para quienes la movilidad es parte de un nuevo "modo de vida urbano" donde la búsqueda de libertad personal por parte del ciudadano se refleja en la posibilidad de circular y desplazarse libremente por el territorio. Distinta es la posición sustentada por Sennett ${ }^{7}$, para quien la transformación de calles, avenidas, estaciones y otros, en áreas de paso y no de permanencia, promueve el aislamiento social entre las personas y con ello el declive del espacio público como ámbito abierto a la expresión de la diversidad sociocultu-

\footnotetext{
Venturi y Scott, 1978.

Op Cit.
} 
ral. Hall ${ }^{8}$, por su parte, establece que las infraestructuras de la movilidad promueven el aumento del tiempo invertido en el traslado diario al trabajo y la ausencia formas urbanas delimitadas y reconocibles culturalmente para los habitantes de las ciudades, mientras que para Castells ${ }^{9}$ el aumento de la movilidad urbana va acompañada por formas neutras, puras y diáfanas propias de la arquitectura posmoderna, que promueven la supresión de los referentes históricos particulares de cada localidad y generan un efecto "desterritorializador" que acentúa "la superación de los lugares en el espacio de los flujos".

La diversidad de posturas y posiciones en relación a las implicancias que la movilidad urbana tiene sobre la vida social no sólo da cuenta de las nuevas problemáticas e interrogantes surgidas frente al tema, sino que también promueve importantes cuestionamientos respecto de la viabilidad de los marcos teóricos y metodológicos actualmente disponibles en las ciencias sociales. En este sentido, y tal como propone Delgado, la movilidad incluso puede llegar a generar nuevas formas de entender "lo urbano" desde una perspectiva sociocultural ${ }^{10}$, las cuales se exploran a continuación.

Hall, 1996.

Castells, 1999

10 “... lo que implica la urbanidad es precisamente la movilidad, los equilibrios precarios de las relaciones humanas, la agitación como fuente de vertebración social, lo que da pie a la constante formación de sociedades coyunturales e inopinadas, cuyo destino es disolverse al poco tiempo de haberse generado"(Delgado, 1999: 12).

\section{La movilidad urbana desde una perspectiva socio-cultural}

En consonancia con el reconocimiento señalado por Sennett a la movilidad urbana, desde las ciencias sociales, y particularmente desde la sociología urbana, ésta ha sido considerada como un componente fundamental en la conformación de una cultura propiamente urbana.

Desde fines del siglo XIX, y alertados principalmente por los efectos que los procesos de modernización, industrialización y urbanización tuvieron sobre la población de Europa central, autores como M. Weber, G. Simmel, F. Tonnies, entre otros, pusieron especial atención en las transformaciones observadas en los modos de vida de las personas. $\mathrm{Su}$ influencia fue sumamente importante en la formación de la escuela de sociología urbana de Chicago, una ciudad donde la velocidad de las transformaciones experimentadas en un lapso de cincuenta años -cambio de siglo mediante-constituía una clara manifestación del surgimiento de un modo de vida particular y distintivo. 
La influencia desarrollada por los ya mencionados Simmel y Tonnies, acogida y consolidada en la obra de R. Park primero y de L. Wirth después, permitió a la sociología urbana norteamericana de principios del siglo XX describir la conformación de dicho modo de vida propiamente urbano, sustentado principalmente en el surgimiento y desarrollo de nuevas formas de sociabilidad caracterizadas por el predominio de vínculos sociales precarios, fragmentarios, transitorios, dispersos y con fuerte énfasis del anonimato, los cuales influyen en la conformación de normas, costumbres, tradiciones e instituciones diferenciados y heterogéneos, de transformación constante y cada vez más acelerada a lo largo del tiempo. Esta formulación es lo que a grandes rasgos se conoce en ciencias sociales como "cultura urbana" 11.

Los aportes desarrollados por los autores mencionados nombrados en torno al concepto de "cultura urbana", y su consecuente evolución a lo largo del tiempo, permiten disponer de un marco de sentido -teórico y metodológico- característico de la vida social en los grandes centros urbanos gracias al cual es posible contextualizar con toda su re-

11 Zoido et al. sintetizan a grandes rasgos los componentes de la cultura urbana en la siguiente definición: "Modo de vida y de comportamiento basado en las relaciones superficiales e impersonales, el individualismo, la segmentación de roles, la competencia, la secularización y la movilidad, que caracteriza a los individuos de las grandes ciudades contemporáneas en contextos de desarrollo económico"(2000: 113). levancia los alcances que la movilidad urbana ha generado en los modos de vida de sus habitantes:

Debido a los continuos desplazamientos que realiza, el individuo entra en contacto con distintos ambientes que sólo conoce fragmentariamente y en los que interacciona con otros individuos de forma parcial. Esta situación también explica que los ciudadanos tiendan cada vez más a aislarse en su hogar, reforzando el protagonismo de la familia y las estrategias particulares frente a los mecanismos de solidaridad vecinal y colectiva" (Zoido et al., 2000: 113).

Esta definición propuesta por Zoido et al. resulta relevante por tres razones. En primer lugar representa una valoración explícita de la importancia que la cultura urbana tiene en el desarrollo de los grandes centros urbanos. En segundo lugar identifica en la movilidad urbana un componente sustancial en su conformación, lo cual abre un campo de investigación fructífero en torno a sus dimensiones socioculturales. Por último, pone en evidencia una tensión clave para su desarrollo conceptual: la movilidad urbana, entendida como parte de la vida cotidiana, amplía y diversifica los ámbitos de experiencia cultural que sus habitantes tienen de 
la ciudad y de sus conciudadanos. Sin embargo, y adicionalmente a lo anterior, disminuye la profundidad de éstas. Esta tensión deja de manifiesto una de las grandes paradojas de la cultura urbana y de la vida social contemporánea, marcada por el establecimiento de relaciones sociales dispersas, motivadas principalmente por la necesidad de desplazamiento por una parte, y la pretensión de relaciones sociales fundadas en experiencias profundas, duraderas y localizadas, representadas por ejemplo en el hogar, el vecindario o barrio, por otra.

No obstante lo anterior, en el campo de los estudios urbanos este reconocimiento no ha sido generalizado. En gran medida se debe al hecho que la cultura urbana ha sido mayoritariamente considerada como mero producto o resultado de los procesos de modernización, industrialización y urbanización experimentados por las sociedades modernas desde mediados del siglo XIX hasta la actualidad.

Asimismo, y particularmente bajo el auge de los enfoques funcionalistas, estructuralistas y marxistas, el concepto y problematización de la cultura urbana experimentó una acentuada tendencia a la invisibilización en las ciencias sociales a mediados del siglo XX. Destaca en este sentido la crítica desarrollada por Castells ${ }^{12}$, quien la consideraba "ideológica" al sustentar una representación superficial e interesada de la realidad, la cual no profun- dizaba analíticamente en los factores estructurales y profundamente capitalistas que subyacían en ella. De esta manera, el concepto de "cultura urbana" fue considerado durante mucho tiempo como meramente descriptivo de la realidad, y por ende insuficiente para abordar las lógicas de dominación y subordinación predominantes en los grandes centros urbanos a mediados de siglo.

Sin embargo, desde mediados de los años ochenta es posible observar enfoques dentro de las ciencias sociales que han rescatado y revalorizado su importancia, destacando la movilidad urbana como un componente sustancial de ella. En este sentido, las ciencias sociales enfrentan el desafío de promover el desarrollo y fortalecimiento de una perspectiva sociocultural de la movilidad urbana que permita comprender la paradoja anteriormente planteada en toda su complejidad. Para ello es necesario establecer algunas consideraciones que den cuenta de su especificidad bajo los actuales procesos de desarrollo urbano orientados bajo la lógica posfordista.

Una primera consideración implica un profundo cuestionamiento a la manera de pensar "lo urbano" desde las ciencias sociales, tradicionalmente sustentado en categorías conceptuales dicotómicas como por ejemplo "rural / urbano", "societario / comunitario", "centralidad / periferia", entre otras.

12 Castells, 2004 
La primera de ellas hace referencia a la existencia de una profunda diferenciación social, política, económica y cultural generada gracias a los acelerados procesos de modernización, industrialización y urbanización experimentados en las sociedades occidentales desde los inicios de la revolución industrial hasta mediados del siglo XX, y que sintetizan un conjunto de diferencias que van desde las estructuras sociales (clases sociales v/s castas), las formas de organización y participación social y política (modelos coloniales v/s republicanos), el modo de producción predominante (agrícola y/o ganadero v/s industriales), el tipo de vínculos y relaciones sociales (presenciales v/s racionales), entre otras. De esta manera, se va conformando la imagen de que existen dos concepciones de mundo distintas, pero igualmente subordinada la una (rural) a la otra (urbana).

Asociada a lo anterior, la distinción entre lo "societario/comunitario" desarrollada y aplicada con particular resonancia por Tonnies, hace referencia tanto a las formas de sociabilidad y de tipos de vínculos sociales diferenciados, como también diferencias importantes entre la voluntad racional y la voluntad natural existentes entre ellas. Una cierta similitud con este modelo puede ser encontrado en Simmel a través de la diferenciación que éste hace entre las características espaciales y culturales de la aldea rural y la pequeña ciudad, distinguidas por la costumbre, el ritmo de vida lento y uniforme, frente a la mutación constante y el ritmo febril de la metrópoli.
Por último, la distinción conceptual entre "centro / periferia" popularizada en las ciencias sociales a mediados del siglo XX, principalmente gracias a la influencia de la "Nueva Sociología Urbana" francesa, dice relación con contradicciones derivadas del funcionamiento del sistema productivo capitalista y de su estructura social característica, fuertemente influida por la existencia de relaciones sociales conflictivas entre clases. Lo anterior repercute no solamente en la localización y en la accesibilidad desigual que éstas tienen respecto de los bienes, productos y servicios generados en las ciudades, sino también en el papel marginal y subordinado que ciertos grupos o clases sociales tienen en el funcionamiento del sistema urbano.

Evidentemente, el uso, relevancia y asidero de las dicotomías anteriormente mencionadas debe ser abordada y comprendida bajo el contexto histórico en el cual fueron planteadas, marcado principalmente por los acelerados procesos de transformación social, político, económico y cultural vivenciados por las sociedades europeas bajo una lógica fordista y cuyas consecuencias fueron vistas con interés y preocupación por los sociólogos de la época. No obstante, en la actualidad el desarrollo de la movilidad urbana pone en cuestión su capacidad heurística en la medida que ella desborda las delimitaciones territoriales permitiendo y promoviendo cruces y mixturas entre lo rural y lo urbano, entre lo societario y lo comunitario, y entre 
el centro y la periferia, los cuales dan cuenta del carácter "flexible" del modelo posfordista ${ }^{13}$.

En directa relación con el reciente planteamiento, una segunda consideración la constituye el cuestionamiento a la tradicional correlación existente en ciencias sociales entre identidad, cultura y territorio. La movilidad urbana permite cuestionar el establecimiento de delimitaciones claras, precisas y permanentes sobre el territorio, y la posibilidad de fundar en ellas la construcción de identidades culturales prístinas y permanentes por parte de los habitantes urbanos. En este aspecto, destaca la formulación de categorías conceptuales discretas, flexibles e individualizadas como por ejemplo el concepto de "lugar".

Sin lugar a dudas, la más difundida de estas propuestas la constituye aquella formulada por $\mathrm{M}$. Augé ${ }^{14}$ bajo los conceptos de "lugar" y "no lugar". Para Augé, el concepto de "no lugar" hace referencia a instalaciones para la circulación acelerada de personas y bienes, puntos de tránsito y ocupaciones provisionales como vías aéreas, ferroviarias, autopistas, y medios de transporte, los cuales constituyen espacios no identitarios -al negar significaciones colectivas para quienes los habitan-,

13 Esta última consideración es particularmente relevante para el caso latinoamericano, principalmente a partir de las teorías de la hibridación cultural desarrolladas por N. García Canclini y su aplicación a los itinerarios de los viajeros urbanos. Augé, 2004. no relacionales -al impedir un reconocimiento participativo entre dichos sujetos respecto de la significación establecida-, y no históricos -al fomentar una mínima estabilidad en los referentes espacio-temporales que son comunes a todos-.

Sin embargo, y a diferencia de la impresión que usualmente se tiene de ellos, para Augé "lugares" y "no lugares" constituyen una polaridad falsa, ya que se entrelazan e interpenetran durante el tránsito de los sujetos urbanos. De esta manera, los "no lugares" componen puntos o artefactos de mediación cuya ocupación nunca representa un fin por sí mismo, sino simplemente un medio. Lo anterior permite comprender ese aspecto de la experiencia urbana que consiste en el permanente tránsito por múltiples y diversas referencias formales, funcionales y de sentido. En definitiva, los "no lugares" constituyen aquellos puntos de la ciudad donde se da el vínculo fugaz y transitorio entre el sujeto y su entorno social y territorial, vínculo que en definitiva deviene absolutamente fragmentario y que es antecedente claro para la generación de relaciones sociales contractuales y para el anonimato ${ }^{15}$.

Una perspectiva similar a la anterior fue sustentada por el antropólogo Ulf Hannerz ${ }^{16}$. Para él, las

15 Para un desarrollo más completo de este aspecto, ver: Augé, 2004: 83 - 98.

16 Hannerz, 1998. 
"ciudades mundiales" como Nueva York, Londres, París y Tokio juegan un importante rol como centros productores de nueva cultura, concentrando las miradas y la atención del resto de ciudadanos del planeta. A su juicio, esta centralidad se desenvuelve en torno a dos niveles distintos de producción cultural. Por un lado, las ciudades mundiales se nutren del conjunto de relaciones sociales que surgen a nivel local y en las cuales participan, de manera más o menos contingente, tanto quienes las habitan permanentemente como aquellos que mantienen un vínculo esporádico y muchas veces circunstancial con ellas, como por ejemplo los viajeros ${ }^{17}$. El segundo nivel es aquél que conjuga los flujos simbólicos de producción cultural que las industrias comunicacionales transportan desde cualquier parte del planeta y que, por asuntos de mercado, convergen con mayor fuerza en ellas. Sin embargo, mientras la primera dimensión convierte a las ciudades mundiales en "lugares", la segunda las convierte en "nodos" dentro de un sistema de redes.

Para Hannerz, la constitución del "lugar" tiene en las calles uno de sus principales referentes, ya que es en ella donde sus habitantes y sus visitantes se convierten no sólo en observadores sino también en protagonistas cotidianos de la vida social. Es en la calle, y gracias al movimiento propio que ella incita, que cada uno de ellos aporta no sólo perspec-

17 Para un desarrollo más completo de este aspecto, ver: Hannerz, 1998: 208 - 213. tivas distintas respecto de los hechos o fenómenos que ocurren día a día, conformando así una "forma de vida" peculiar y característica que tiene en la experiencia directa y real su principal instrumento de reproducción cultural. De esta manera es posible establecer la distinción entre todos aquellos que aprehenden una imagen virtual de una ciudad por medio de la televisión, las revistas, internet, etc. quienes presentan la tendencia a convertir determinados bienes o tradiciones más llamativos en signos, es decir, a asumir una representación cerrada, limitada y contingente de lo que ven, y aquellos que gracias a la experiencia de la calle, mucho más abierta y connotativa, logran una visión claramente simbólica ya que lo trascendente no es sólo la construcción de una imagen sino más bien el acto mismo de ver, oír y oler.

Una tercera consideración implica atender a lo que Bauman ${ }^{18}$ denomina como la "aceleración" de la vida social urbana. De acuerdo con este autor, algunas de las claves del pensamiento moderno como por ejemplo la concepción disociada del tiempo y del espacio y el predominio del primero sobre el segundo, sumado al desarrollo tecnológico informático y de las comunicaciones, han propiciado el control de la velocidad de movimiento a través del espacio, lo cual ha sido posible gracias al desarrollo de distintos medios o instrumentos de

18 Bauman, 2006.

ARTíCULO: Dimensiones culturales de la movilidad urbana / Carlos Lange Valdés 
movilidad que van desde la construcción de autopistas y líneas de metro hasta los vehículos motorizados que sustituyen la fuerza humana y animal, los cuales modifican las formas y velocidades de desplazamiento y con ello fortalecen la relación de predominio del tiempo sobre el espacio. Empero, Bauman establece que este supuesto predominio ha llegado a su fin en la medida que la aceleración del tiempo sobre el espacio ha alcanzado su "límite natural" como lo es la "instantaneidad" de los acontecimientos.

Asimismo, la importancia adquirida por los medios e instrumentos de movilidad en las sociedades contemporáneas ha favorecido lo que él denomina como una "cultura del nomadismo", la cual se desarrolla por sobre la "cultura del sedentarismo". Esta distinción cultural genera importantes consecuencias en la constitución de los vínculos sociales y en la organización de las diferencias sociales dentro de las sociedades contemporáneas, que se expresa principalmente en el distanciamiento entre las clases dirigentes y el resto de la sociedad. El acceso a los medios e instrumentos de movilidad permite afianzar las posiciones de poder de las clases sociales dirigentes y con ello su nomadismo, frente al resto de la sociedad caracterizada por su sedentarismo.
En este sentido, para Bauman la cultura del nomadismo propicia "el fin de la era del compromiso mutuo", en la medida que la huida, el escurrimiento y la capacidad de evitar el contacto con otros constituye un instrumento de poder que es utilizado por las clases dirigentes frente a las clases sociales más desfavorecidas, aumentando con ello la distancia sociocultural y espacial entre unas y otras. Esta característica, que propicia procesos de exclusión y segregación social urbana en la medida que promueve la ruptura de vínculos sociales entre distintos grupos sociales, refleja el carácter extraterritorial del poder que gozan las clases dirigentes, es decir, su capacidad para ejercer el poder político y económico más allá de los espacios sociales comunes. En este plano, y siguiendo la distinción entre las "elites globales" y la "gente local" propuesta por Castells, Bauman establece que a partir del fin del panóptico, las clases dirigentes se configuran como "amos ausentes" 19.

El planteamiento desarrollado por Bauman tiene interesantes implicancias para comprender otras problemáticas sociales, como por ejemplo, los procesos de exclusión social y de segregación socioespacial que se observan en las sociedades contemporáneas y que se concentran principalmente en los grandes centros urbanos. Sin embargo, y a

19 "Estamos asistiendo a la venganza del nomadismo contra el principio de la territorialidad y el sedentarismo. En la etapa fluida de la modernidad, la mayoría sedentaria es gobernada por una élite nómade y extraterritorial" (ibid: 18).

revista invi № 71 / Mayo 2011 / Volumen № 26: 87-106 
diferencia de lo que podría ser su abordaje desde enfoques y lógicas sociales dicotómicas, este tipo de problemáticas implican una revisión de las relaciones y vínculos sociales existentes entre grupos sociales diferentes y desiguales.

Por último, una cuarta consideración implica atender a la importancia de la movilidad urbana como un fenómeno de la vida cotidiana de los habitantes urbanos. Ésta aparece como una consideración fundamental en la medida que apunta a la posibilidad y a la vez a la necesidad comprensiva de distinguir entre la movilidad como una condición de los sistemas urbanos considerados genéricamente, y la movilidad como una forma de experiencia sociocultural que pone a los habitantes de la ciudad, y por ende a sus prácticas y experiencias particulares, en el primer plano de cualquier formulación teórica y metodológica ${ }^{20}$.

Esta consideración a la dimensión cotidiana de la movilidad urbana conlleva un cambio en las concepciones de sociabilidad. Tradicionalmente las ciencias sociales han trabajado sobre una clara distinción entre vínculos sociales primarios o presenciales, secundarios o racionales, y terciarios o virtuales. Con el aumento de la movilidad urbana

20 Siguiendo la definición propuesta por Jirón et al., la movilidad urbana cotidiana puede ser definida como "aquella práctica social de desplazamiento diario a través del tiempo y espacio urbano que permite el acceso a actividades, personas y lugares" (2010: 24). cotidiana, la claridad y rigidez de este tipo de distinciones comienza a disolverse en la medida que el desarrollo de la vida social aparece fuertemente marcado por el aumento de las distancias y de las co-presencias intermitentes en ámbitos territorialmente difusos, lo que significa que los distintos tipos de vínculos sociales comienzan a cruzarse y mezclarse con mayor frecuencia.

En este sentido, la movilidad urbana cotidiana facilita a los habitantes urbanos el permanente tránsito entre distintos ámbitos de interacción social, distintas escalas territoriales y distintos sectores de la ciudad, y con ello evidentemente también distintas realidades socioculturales. La particularidad de esta aproximación es que estos distintos ámbitos se mezclan, cruzan y yuxtaponen generando experiencias diferenciadas de sociabilidad.

El primer ámbito hace referencia a experiencias de sociabilidad urbana vinculadas al ámbito de lo íntimo, es decir, aquél que se constituye a partir del sujeto en relación a sí mismo, sus propios pensamientos, sensaciones, deseos y expectativas, entre otras. Por una parte ello incluye el propio cuerpo, pero también sus extensiones más inmediatas vinculadas a sus relaciones sociales dentro del hogar. 
Un segundo ámbito de experiencias de sociabilidad refiere al mundo privado, es decir, aquél constituido por vínculos sociales de carácter primario, resguardados en la vivienda y el entorno más inmediato, como son la familia, los amigos y el vecindario. Éste constituye el ámbito por excelencia de la presencia y de los vínculos sociales marcados por su carácter emocional, como son el amor, la comensalidad, entre otros.

Un tercer ámbito de experiencias de sociabilidad refiere a lo comunitario, es decir, aquél que se constituye a partir de redes interpersonales de afinidad particular: grupos vecinales, religiosos, políticos, profesionales, deportivos, etc. (conjunto habitacional, el barrio).

Por último, el ámbito público se constituye a partir de relaciones sociales establecidas entre "conocidos de vista" y extraños, rigiéndose tanto por valores como la superficialidad, la contingencia, la individualidad y por cierto, y de manera muy importante, también el anonimato.

La consideración acerca del cruce, mezcla y/o yuxtaposición entre estos distintos ámbitos de experiencia de sociabilidad en la vida cotidiana permite tanto una apertura hacia la diversidad so- ciocultural como también un reconocimiento a la particularidad de cada habitante urbano según las actividades, funciones, roles, estatus, entre otras consideraciones, que realice en su vida cotidiana y que posibilitan formas de "sociabilidad híbrida".

En este sentido, las ciencias sociales requieren desarrollar enfoques teóricos y metodológicos transversales que den cuenta justamente de las discretas "fronteras" en las cuales se articulan los distintos ámbitos antes mencionados. Siguiendo los planteamientos desarrollados por Augé ${ }^{21}$ en torno a este punto, dichas "fronteras" entre distintos ámbitos de interacción y sociabilidad pueden constituirse tanto en zonas "de paso" como de "encuentro". En ambas es posible visualizar la presencia del "otro", con las distintas expectativas y/o aprehensiones que ello implica.

Sintetizando los planteamientos expuestos, la comprensión de la movilidad urbana desde una perspectiva sociocultural conlleva no sólo un replanteamiento de algunas posiciones tradicionales dentro de las ciencias sociales, sino que también implica avanzar hacia una comprensión de "lo urbano" que dé cuenta de su carácter complejo y multidimensional22, marcado por la constitución

21 Auge, 2007.

22 En este sentido, y a modo de ejemplo, cabe destacar la definición propuesta por Delgado, para quien "lo urbano no está constituido por estructuras estables, sino más bien por un orden de relaciones sociales por lo general impersonales, superficiales $y$ segmentarias" (Delgado, 2007: 182)

revista invi ํำ 71 / Mayo 2011 / Volumen № 26: 87-106 
de formaciones culturales "líquidas" y fluctuantes, cada vez más individualizadas, deslocalizadas y móviles. Esta apertura hacia nuevas formas de entender "lo urbano" aparece directamente asociada a las transformaciones observadas en el carácter moderno de las sociedades contemporáneas, donde la movilidad juega un papel fundamental en la constitución de lo que se ha denominado como "modernidad tardía", "modernidad líquida", entre otras conceptualizaciones.

Sin embargo, la comprensión de la movilidad urbana desde una perspectiva sociocultural no solamente conlleva requerimientos y cuestionamientos a los enfoques desarrollados desde las ciencias sociales, sino también genera nuevas interrogantes que deben ser abordadas convenientemente, algunas de las cuales se exponen a continuación.

\section{Interrogantes para el estudio de la movilidad urbana desde las ciencias sociales}

Tal como se ha planteado a lo largo de estas páginas, la movilidad urbana incide fuertemente en los modos de vida de los habitantes urbanos promoviendo una paradoja sustentada entre la ampliación y diversificación de sus experiencias culturales y de las relaciones sociales asociadas a ellas, a la vez que promueve un debilitamiento de las

100 revista invi № 71 / Mayo 2011 / Volumen № 26: 87-106 mismas, que incide en el establecimiento de vínculos y relaciones sociales coyunturales, dispersos, precarios entre ellos.

No obstante, junto con las consideraciones propuestas en el apartado anterior, y en cierta medida derivada también de ellas, surgen algunas interrogantes que se proponen a continuación. Sin lugar a dudas, el eje transversal de las nuevas interrogantes aquí planteadas lo constituye la paradoja anteriormente mencionada, la cual constituye aún un desafío pendiente para las ciencias sociales.

Una primera interrogante dice relación con el surgimiento de nuevos ámbitos de sociabilidad.

A juicio de Augé, una de las consecuencias del aumento de la movilidad urbana lo constituye el "descentramiento" de los tradicionales espacios de sociabilidad. Frente al cruce y la yuxtaposición de los ámbitos de sociabilidad referidos en el apartado anterior, los habitantes urbanos pierden la claridad de aquellas referencias que les permitían sentir la ciudad como parte de su mundo conocido y dentro de los cuales estaban el hogar, el barrio, el trabajo, los clubes sociales y deportivos, o también aquellos espacios de uso público usualmente concebidos como espacios de encuentro e interacción entre extraños, como los parques, plazas y calles.

En este aspecto, la movilidad urbana propicia la conformación de nuevos tipos de "lugares", muchos de los cuales se generan precisamente gracias

ARTíCULO: Dimensiones culturales de la movilidad urbana / Carlos Lange Valdés 
al movimiento, y se convierten en nuevos espacios de sociabilidad, "lugares" intermedios entre lo público y lo privado. Tal y como lo plantea Jirón ${ }^{23}$ a a través de la movilidad urbana cotidiana es posible que los espacios de transporte público y privado -como el metro, el bus o el automóvil particular-, así como los espacios de tránsito o estancia corta-como las escaleras de un centro comercial, los andenes de una estación de transporte o la sala de espera de un aeropuerto-, entre otras, pueden constituirse en "lugares móviles" y "lugares transientes", acogiendo nuevas formas de encuentro y sociabilidad.

Frente a esta afirmación surge la interrogante: ¿Qué similitudes y diferencias existen entre los espacios tradicionales de sociabilidad y aquellos considerados como nuevos tipos de "lugares"?

Una segunda interrogante dice relación con los usos, prácticas y estrategias de permanencia y desplazamiento que dan vida a estos nuevos tipos de "lugares". En el entendido que permanencias y desplazamientos no necesariamente constituyen formas de uso y apropiación excluyentes del espacio urbano, sino más bien tienden hacia formas de complementariedad ${ }^{24}$, es posible identificar una gran diversidad de habitantes de la ciudad que desarrollan su vida cotidiana bajo su dinámica: trabajadores ambulantes, kiosqueros, taxistas,

23 Jirón, 2010.

24 Lange, 2004 cuidadores de autos, estafetas e incluso paseantes eventuales, entre otros.

De acuerdo a Delgado ${ }^{25}$, y siguiendo también un postulado desarrollado en su momento por De Certeau ${ }^{26}$, los habitantes urbanos regulan sus interacciones con otros a través de una especie de "teoría práctica", es decir, mediante la aplicación de un conjunto de pautas surgidas de su razonamiento empírico que les permite establecer una dinámica de racionalidad y normalidad en el uso del espacio público.

Frente a esta afirmación, surge la interrogante: ¿Qué tipos de usos, prácticas y estrategias regulan la sociabilidad de los habitantes urbanos en los nuevos tipos de "lugares"?

En la misma senda, y frente a la creciente preponderancia adquirida por la movilidad urbana en la actualidad, surge una tercera interrogante que apela a la emergencia de los transeúntes como protagonistas de las transformaciones culturales de "lo urbano" actualmente en curso.

El transeúnte se define como aquel habitante del espacio urbano que "está de paso". Sin embargo, y más allá de la discreta fugacidad y contingencia que conlleva esta simple definición, el transeúnte goza de un agudo pragmatismo que le permite percibir los ritmos que marcan su trayectoria y sor-

25 Delgado, 2007.

26 De Certeau, 2000. 
tear con éxito cualquier atisbo de incidencia que pueda obstruirla ${ }^{27}$. En este sentido, sería posible considerar al transeúnte como un fiel exponente de los usos, prácticas y estrategias de sociabilidad abordados en la interrogante anterior.

De acuerdo con Delgado ${ }^{28}$, el transeúnte va significando los espacios de movilidad urbana combinando el anonimato, la indiferencia y la distinción, dependiendo de las necesidades, recursos, intereses y/o expectativas que orienten su actuar, lo cual devela importantes facultades reflexivas presentes en sus pautas de comportamiento.

Considerando el carácter reflexivo de los transeúntes ¿es posible considerarlos potenciales actores sociales urbanos?

Una cuarta interrogante, directamente asociada con la anterior, alude al surgimiento de nuevas formas de participación social asociadas a la movilidad urbana.

Si bien a lo largo de este trabajo se ha reconocido en la movilidad urbana un factor preponderante en la creación de vínculos sociales laxos, coyun-

27 Joseph, 1988.

28 Delgado, 2007. turales y transitorios, algunos autores reconocen en esta condición un indicio en la conformación de grupos sociales con identidades flexibles, sentimientos de pertenencia aleatorios y formas de organización informales, expresión de las sociabilidades híbridas ya reseñadas.

Ejemplos de lo anterior serían las "redes sociales espacialmente dispersas" propuestas por Cucó Giner ${ }^{29}$ o las "movilizaciones" propuestas por Delga$\mathrm{do}^{30}$. Estas últimas destacan por su capacidad colectiva de apropiación de espacios urbanos, donde la multitud se vuelve "fusional" expresándose a través de fiestas y celebraciones religiosas, conmemoraciones ciudadanas, manifestaciones políticas, eventos deportivos, etc ${ }^{31}$.

Considerando la emergencia de estas nuevas formas de participación social, ¿qué relevancia e incidencia tienen éstas en el desarrollo de los grandes centros urbanos?

Por último, cabe destacar que en la misma sintonía de Castells ${ }^{32}$ cuando distinguía entre el acceso preferencial de las élites al "espacio de los flujos" v/s el acceso forzoso de las masas populares al "espacio

\footnotetext{
29 Cucó Giner, 2004.

30 Delgado, 2007.

31 De acuerdo con el autor, las movilizaciones urbanas pueden ser entendidas como "dispositivos de reificación de identidades habitualmente negadas en la vía pública", lo cual supone un reconocimiento de diferencias en un contexto de igualación e invisibilización cultural. (lbid: 165).

32 Castells, 1999.
} 
de los lugares", Bauman establece "el fin de la era del compromiso mutuo" expresado en la cultura del nomadismo que las clases dirigentes adoptan para evitar el contacto con las clases sociales más desfavorecidas, ancladas en una cultura del sedentarismo. Asimismo, y de acuerdo con Augé ${ }^{33}$, en la actualidad puede observarse un aumento de las "zonas vacías y porosas" en las cuales se concentran las desigualdades, contradicciones y tensiones históricas engendradas por el sistema urbano.

En estas perspectivas se trasluce la idea de que la movilidad urbana favorece la exclusión social en la medida que acentúa el acceso desigual a los recursos que el modelo de producción posfordista deposita en los grandes centros urbanos.

Sin embargo, y tal como se ha planteado en párrafos precedentes, aún es posible cuestionar la existencia de una estricta correlación entre movilidad urbana y exclusión social, toda vez que aquella pudiera abrir la posibilidad a los grupos sociales más carenciados de acceder a actividades, personas y lugares, entendidos como recursos desarrollados por los habitantes urbanos a partir de su uso y apropiación del espacio habitado ${ }^{34}$.

Considerando el amplio margen de posibilidades que supone la relación inclusión - exclusión social, es posible plantear aquí la interrogante ila movilidad urbana promueve la inclusión o la exclusión social?

Las interrogantes planteadas en este apartado son de carácter genérico y posiblemente no supongan mayor novedad para aquellos investigadores dedicados a abordar las problemáticas derivadas del aumento de la movilidad urbana. Asimismo, muchas de ellas se encuentran actualmente sujetas a procesos de investigación. No obstante esto, todas se mantienen abiertas y por ende susceptibles de ser abordadas por nuevos programas de investigación. En este sentido, constituyen un desafío teórico y metodológico para las ciencias sociales en la medida que ellas requieren el desarrollo de nuevos enfoques de carácter transversal, que sean capaces de superar las viejas dualidades teóricas y metodológicas.

\section{Conclusiones}

El trabajo presentado en estas páginas sustenta que la preponderancia alcanzada por la movilidad urbana en el desarrollo de los grandes centros urbanos orientados bajo el modelo posfordista conlleva importantes transformaciones políticas, económicas y socioculturales. Particularmente en esta última dimensión, la movilidad urbana su-

33 Augé, 2007.

34 Jirón et al., 2010. 
giere una nueva forma de entender "lo urbano", la cual incorpora todas aquellas variables que dicen relación con los modos de vida de los habitantes.

Sin embargo, y dada su novedad, éste constituye un campo abierto para la investigación en ciencias sociales, incorporando nuevas problemáticas e interrogantes que requieren la revisión de los marcos de sentido -teóricos y metodológicos- tradicionalmente utilizados, así como también su reformulación en aquellos aspectos considerados más débiles.

Dicha revisión, y eventualmente su reformulación, pasan necesariamente por reconocer la importancia de la cultura urbana para el desarrollo urbano contemporáneo así como también la relevancia que la movilidad urbana posee en su conformación. Particularmente la movilidad urbana promueve nuevas formas de sociabilidad, transformando las experiencias culturales de habitar la ciudad y con ello los vínculos y relaciones sociales establecidos por sus habitantes.

En este sentido resulta clave reconocer la importancia de una paradoja que marca la transformación de la vida social urbana bajo el contexto de la transición que significa el paso desde el modelo fordista hacia el modelo posfordista, como es la preponderancia adquirida por los vínculos y relaciones sociales transitorios y circunstanciales frente a la pretensión tradicional asociada a vínculos y relaciones sociales perdurables y permanentes.
Es en torno a esta paradoja que las ciencias sociales poseen un campo de investigación abierto y prolífico, tanto en lo que respecta a nuevos requerimientos y consideraciones teóricas y metodológicas como en lo que refiere a nuevas interrogantes para abordar.

\section{Referencias Bibliográficas}

AUGÉ, Marc. Los "no-lugares", espacios del anonimato. Barcelona, España, Gedisa, 2004, 125 p. ISBN 8474324599 .

AUGÉ, Marc. Por una antropología de la movilidad. Barcelona, España, Gedisa, 2007. 96 p. ISBN 8497842358.

BAUMAN, Zygmunt. Modernidad líquida. Buenos Aires, Argentina, Fondo de Cultura Económica, 2006, 232 p. ISBN 9505575130.

BERMAN, Marshall. Todo lo sólido se desvanece en el aire: La experiencia de la modernidad. México DF, México, Siglo XXI, 1998, 386 p. ISBN 9682315093

CASTELLS, Manuel. La cuestión urbana. México DF, México, Siglo XXI, 517 p. 2004. ISBN 9682321735

CASTELLS, Manuel. La era de la información: economía, sociedad y cultura Vol I; La sociedad Red. Madrid, España, Siglo XXI, 1999. ISBN 9682321670.

CASTELLS, Manuel. La era de la información: economía, sociedad y cultura Vol II; La fuerza de la

ARTíCULO: Dimensiones culturales de la movilidad urbana / Carlos Lange Valdés 
identidad. Madrid, España, Siglo XXI, 1999. ISBN 9682321670.

CUCÓ I GINER, Josepa. Antropología urbana. Barcelona, España, Ariel, 2004, 244 p. ISBN 8434422220

DE CERTEAU, Michel. La invención de lo cotidiano. $1^{a}$ reimp. México DF, México, Universidad Iberoamericana, 2000, 229 p. ISBN 9688592595.

DELGAD0, Manuel. El animal público. Barcelona, España, Anagrama, 1999, 218 p. ISBN 8433905805

DELGADO, Manuel. Sociedades movedizas. Barcelona, España, Ed. Anagrama, 2007, 275 p. ISBN 9788433962515.

GARCÍA CANCLINI, Néstor. Imaginarios urbanos. Bs. Aires, Argentina, Ed. EUDEBA, 1997, 149 p. ISBN 950-23-0670-8.

GARCÍA SELGAS, Fernando. "Posthumanismo y ciencias sociales: una introducción". En: Politica y Sociedad. 45 (3): 7-15, 2008. ISSN: 1130-8001.

HALL, Peter. Ciudades del mañana. Historia del urbanismo en el siglo XX. Barcelona, España, Ed. del Serval, 1996, 494 p. ISBN 8476281900.

HANNERZ, Ulf. Exploración de la ciudad. Hacia una antropología urbana. México DF, México, FCE, 1993, 387 p. ISBN 8437503698.

HANNERZ, Ulf. Conexiones transnacionales. Madrid, España, Cátedra, 1998, 296 p. ISBN 8437616298.

HARVEY, David. La condición de posmodernidad. Buenos Aires, Argentina, Amorrortu 2004, 401 p. ISBN 9505186525.
JIRÓN, Paola; LANGE, Carlos y BERTRAND, María. "Exclusión y desigualdad espacial: Retrato desde la movilidad cotidiana". En: Revista INVI. 25 (68): 15-57, Mayo 2010. ISSN: 0718-1299.

JIRÓN, Paola. "Repetition and difference: rhythms and mobile place-making in Santiago de Chile". En: EDENSOR, T (ed). Geographies of rhythm: nature, place, mobilities and bodies, Ashgate Publishing, Aldershot, 2010, p. 129-143. ISBN 9780754676621

JOSEPH, Isaac. El transeúnte y el espacio urbano: ensayo sobre la dispersión del espacio público, Buenos Aires, Argentina, Gedisa, 1988, 159 p. ISBN 950911345X

IMILAN, Walter y LANGE, Carlos. "Aproximación a la antropología urbana chilena: lo urbano y el trabajo de campo en la ciudad". En: RICHARD, Nicolás (ed). Movimiento de campo: en torno a cuatro fronteras de la antropología en Chile. Guatemala, ICAPI, 2003, p. 27 - 44.

LANGE, Carlos. Espacios públicos, movilidad y sujetos urbanos. Tesis para optar al grado de Magíster en Desarrollo Urbano, Santiago, Pontificia Universidad Católica de Chile. [En línea] Cultura urbana. 2004. Disponible en: http://cultura-urbana. $\mathrm{cl} / \mathrm{p}=143$.

PARK, Robert. "Ecología Humana". En: THEODORSON, G. A. Estudios de ecología humana. Barcelona, España, Labor, 1974, 469 p. ISBN 8433530275

revista invi № 71 / Mayo 2011 / Volumen № 26: 87-106 105 
SASSEN, Saskia. "Ciudades en la economía global: enfoques teóricos y metodológicos". En: EURE, 24 (71), p. 5-25, marzo 1998. ISSN 0250-7161.

SENNET, Richard. Carne y piedra. El cuerpo y la ciudad en la civilización occidental. Madrid, España, Alianza, 2002. 452 p. ISBN 9788420694894.

SIGNORELLI, Amalia. Antropología urbana. Barcelona, España, Antrophos, 1999. 252 p. ISBN 8476585624.

SIMMEL, George. Sociología. Madrid, España, Alianza, 1986. ISBN 8420624799.

TONNIES, Ferdinand. Principios de sociología. México DF, México, Fondo de Cultura Económica, 1987. ISBN 9681625080.
URRUTIA, Víctor. Para comprender qué es la ciudad. Navarra, España, Verbo Divino, 1999, 189 p. ISBN 8481693057.

VENTURI, Robert et al. Learning from Las Vegas. Barcelona, España, Gustavo Gili, 1978, 228 p. ISBN 8425217490 .

WEBER, Max. La ciudad. Madrid, España, De la Piqueta, 1987, 224 p. ISBN 8474430445.

WIRTH, Louis. El urbanismo como modo de vida. Buenos Aires, Argentina, Ediciones 3, 1962, 41 p.

ZOIDO, Florencio et al. Diccionario de geografía urbana, urbanismo y ordenación del territorio. Barcelona, España, Ariel, 2000, 406 p. ISBN 8434405199. 